\title{
Review
}

\section{Left Ventricular Hypertrophy in Hypertension: Stimuli, Patterns, and Consequences}

\author{
Richard B. Devereux and Mary J. Roman
}

\begin{abstract}
Left ventricular ( $\mathrm{LV}$ ) size in childhood closely parallels body size, whereas in adulthood LV mass is increasingly affected by effects of obesity, hypertension, the level of cardiac volume load, and the level of LV myocardial contractility. Recently, additional independent associations of diabetes, arterial structure and function and as yet unknown genes with higher LV mass have been defined; angiotensin II and insulin have also been suggested to be additive stimuli to LV hypertrophy. Consideration of the level of LV mass and of the LV wall thickness/chamber radius ratio (relative wall thickness) has identified four different geometric patterns of $L V$ adaptation to hypertension, including concentric $L V$ hypertrophy (increased mass and wall thickness), eccentric hypertrophy (increased mass, normal relative wall thickness), concentric remodeling (increased relative wall thickness with normal mass) and normal LV geometry. Concentric hypertrophy is associated with especially high arterial pressure while eccentric hypertrophy is associated with obesity and elevated volume load. Numerous studies show that increased LV mass predicts cardiovascular events and death independently of all conventional risk factors; initial studies have also identified adverse implications of low LV midwall function and high relative wall thickness. Pioneer studies strongly suggest that reversal of $\mathrm{LV}$ hypertrophy is associated with an improved prognosis. (Hypertens Res 1999; 22: 1-9)
\end{abstract}

Key Words: hypertension, echocardiography, left ventricular hypertrophy, left ventricular function

Since the mid 1970 s, methods to measure left ventricular (LV) mass by echocardiography or by other techniques (1) have been used to show that LV hypertrophy (LVH) is more prevalent, more heterogeneous in its anatomic and pathophysiologic patterns, and a stronger determinant of outcome in hypertensive patients than was previously recognized. In this article, we will examine stimuli of hypertensive $\mathrm{LVH}$, review its geometric patterns, and discuss the consequences of LVH with respect to cardiac function and outcome.

\section{Stimuli Promoting}

The LV normally grows continuously from infancy until adulthood (2), with cellular enlargement (hypertrophy) accounting for most of the increase in size. Further increases, or at times decreases, in LV muscle mass may occur due to physiologic or pathologic alterations in hemodynamic load. In apparently normal individuals, the closest correlate of LV mass is body size in both children and adults (2-3). Body size has traditionally been taken into account by indexing LV mass for body surface area. This method of LV mass indexation is useful in detecting
LVH due to hypertension, but may misclassify obesity-induced LVH as normal (4). A physiologic approach to the problem imposed by obesity is to index LV mass for lean body mass (5), but this is impractical for routine purposes. Alternatively, body height to the power of its allometric (or growth) relationship with LV mass can be used to index the latter variable (6). After puberty, men have a larger LV mass than women in relation to body size. LV mass/body surface area or height ${ }^{2.7}$ are $10 \%$ to $20 \%$ greater in normal men than women. This difference parallels the sex difference in lean body mass and may reflect genetic, hormonal, or exercise effects that influence both skeletal and heart muscle. Relations between age and LV dimensions or mass are either absent or weakly positive - especially in women - in normal adults. Thus, body size and sex need to be taken into account when establishing upper normal limits for LV mass, while age in women and systolic blood pressure in the normal range contribute minimally to multivariate predictive models.

In addition to demographic factors, hemodynamic variables play an important role in determining $\mathrm{LV}$ mass. Our understanding of the full impact of blood

From the Department of Medicine, The New York Presbyterian Hospital and Weill Medical College of Cornell University, New York, USA.

Address for Reprints: Richard B. Devereux, M.D., Division of Cardiology, Box 222, The New York Hospital-Cornell Medical Center, 525 East 68th Street, New York, NY 10021, USA.

A part of this article was presented at the 21st Annual Meeting of the Japanese Society of Hypertension in Hiroshima 1998.

Received October 20, 1998. 
pressure on the heart has been enhanced by use of ambulatory blood pressure monitoring. LV muscle mass or wall thicknesses are more closely related to 24-h than to casual blood pressures (7). A study in an employed population revealed that both ambulatory blood pressure and LV mass were higher in subjects with jobs characterized by high "job strain" (i.e., high psychological job demands and low decision-making latitude) $(8)$, a variable that is in turn related to an increased risk of cardiovascular morbidity. In a study of normotensive and hypertensive adults (9), patients with concentric LV hypertrophy (increased LV mass and relative wall thickness) had the highest daytime and work systolic and diastolic pressures, while those with eccentric hypertrophy [a geometric pattern associated with increased cardiac output (10)] had significantly lower ambulatory than clinical pressures. Exaggerated blood pressure increases during usual physical activity may also contribute to the development of LVH.

Numerous studies have shown that obesity is associated with increased LV mass $(3-4,11)$. High salt diets have also been linked to hypertensive LVH (12). Both of these factors may increase LV stroke volume, thereby increasing LV chamber volume and predisposing to eccentric LVH. The important role of volume load in the pathogenesis of hypertensive $\mathrm{LVH}$ is underscored by the fact that LV chamber size and stroke volume are more closely related than systolic pressure to LV mass in normotensive and mildly hypertensive humans $(13,14)$ as well as in a general population sample (15). In addition to hemodynamic pressure and volume load, LV mass is affected by a negative relation between LV contractility and myocardial mass (1315). In a recent epidemiologic study, we found that almost half of the variability in LV mass is associated with inter-individual differences in stroke volume, LV contractility, systolic blood pressure, body mass indexes, and gender (15).

\section{Non-Hemodynamic Stimuli Promoting LV Hypertro- phy}

Considerable attention has been devoted recently to the possible contribution of non-hemodynamic factors to LVH. The concept that activity of the adrenergic system, renin-angiotensin system, or both may modulate myocardial hypertrophy is of intense biological interest, based initially on experimental studies that we have discussed previously (16). Lack of well-tolerated, potent $\alpha$-adrenoceptor antagonists as antihypertensive agents has limited human research on the contribution of sympathetic overactivity to LVH. In contrast, several cross-sectional human studies have found associations between circulating angiotensin II levels and LV mass (17-19), and clinical trials have suggested that angiotensin-converting enzyme inhibitors may be especially effective in inducing regression of human LVH $(20,21)$. However, an independent role of circulating or intracellular renin-angiotensin systems in hypertensive LVH remains unproven because of conflicting observations (22).
Another stimulus to LVH that has been identified relatively recently is altered insulin and glucose metabolism. Evidence has been obtained that insulin may be a myocardial growth factor (23). In addition, large epidemiologic studies have shown that adults with diabetes have higher LV mass, independently of other stimuli to LVH $(24,25)$. This relationship may be especially important in view of the increasing prevalence of diabetes in many populations, due at least in part to popularization of "heart-healthy" high carbohydrate diets.

Increasing evidence from phenotypic studies documents genetic influences. Normotensive offspring of hypertensive parents have greater than normal LV mass (26), but this may be related to higher 24-h blood pressure levels (27). Twin studies have shown an influence of heredity on LV mass, which is decreased but still significant after blood pressure, body size, and physical activity are taken into account $(28-30)$. Of even greater importance, three major epidemiologic studies have shown that LV mass is substantially heritable, independent of the effects on LV mass of hemodynamic factors, body build, gender, age, and diabetes (31-33). With addition of the contributions of diabetes and of phenotypic heritability, at least $60 \%$ of the variability of LV mass appears to be explained by demographic and hemodynamic factors, diabetes, and as yet unexplained phenotypic heritability.

Increased LV Mass as a Precursor of Hypertension The possibility that LVH might not only be a consequence of hypertension but could also precede it was first raised by the observation that baseline LV mass in children and adolescents contributed independently to predicting their blood pressure $4 \mathrm{yr}$ later (34). To assess whether this also occurred in adults, we compared baseline findings in 117 normal subjects who remained normotensive and diseasefree $5 \mathrm{yr}$ later with those in 15 individuals from the same population in whom borderline hypertension developed (35). The strongest predictor of subsequent hypertension was initial LV mass, with additional independent prediction by the 24-h urinary sodium/potassium excretion ratio (35). Subsequent studies $(36,37)$ have confirmed the ability of high baseline values of $\mathrm{LV}$ mass to predict subsequent increases in blood pressure, independently of standard risk factors for hypertension. These results raise the possibility that LV mass is more closely linked than is blood pressure to the etiology of hypertension, or conversely that some individuals may have elevated ambulatory blood pressures but normal clinic pressures, a phenomenon we have termed "white coat normotension (38)."

\section{Relation between LV and Arterial Findings}

Accurate noninvasive ultrasound imaging of large arteries and the heart has allowed in vivo comparison of human cardiac and vascular structure and of the impact of altered vascular properties on ventricular adaptation. Direct ultrasound measurement of carotid artery structure in untreated, asymptomatic hypertensive patients demonstrates greater abso- 
lute $(0.89 \pm 0.21$ vs. $0.71 \pm 0.15 \mathrm{~mm}, p<0.00005)$ and relative $(0.30 \pm 0.07$ vs. $0.26 \pm 0.06, p<0.005)$ common carotid artery wall thicknesses than those in matched controls (39). A significant univariate relation between carotid and LV wall thicknesses ( $r$ $=0.40, p<0.005$ ) remained independent in multivariate analyses in which age and blood pressure were taken into account. In that study, vascular hypertrophy was more common than LV hypertrophy (28\% vs. 14\%) among hypertensive patients. A positive relation between evidence of arterial dysfunction and LV mass in normal adults suggests that vascular hypertrophy may precede or play a role in stimulating LVH (40). In addition, we have demonstrated a relation between abnormalities of systemic arterial structure and function, on the one hand, and abnormal LV myocardial function, on the other (41).

Interaction of Stimuli Promoting Hypertensive LVH Increases in LV mass are stimulated by higher blood pressure or stroke volume, as well as by impaired myocardial contractile performance. Based on evidence of the independent relations of these factors to LV mass, we developed a 3-dimensional diagram in which one can move from a surface representing average normal LV mass to one representing LV hypertrophy due to increases in blood pressure or stroke volume or to decreases in contractile efficiency (13). This conceptual schema explains why LV mass does not decrease when blood pressure is reduced by vasodilator drugs that increase stroke volume or by isotonic exercise training, and why it remains normal in hypertensive patients with supranormal LV performance. In our initial study, LV mass was better predicted by these three mechanical stimuli in multivariate analysis than by blood pressure alone $\left(R^{2}=0.66\right.$ vs. 0.20$)$ (13), and the overall $R^{2}$ can be increased further by additional consideration of factors such as diabetes and phenotypic heritability. Potential additional roles of the adrenergic and renin-angiotensin systems continue to be actively investigated.

\section{Left Ventricular Geometric Patterns in Hypertension}

About $5 \%$ of patients with mild to moderate essential hypertension have electrocardiographic (ECG) LVH (42). In contrast, echocardiographic LV mass is increased in from $12 \%$ to $30 \%$ of relatively unselected hypertensive adults, and in $20 \%$ to $60 \%$ of patients with uncomplicated hypertension seen at referral centers (43). These differences reflect in part the known difference in sensitivity for $\mathrm{LVH}$ between ECG and echocardiography (44). In addition, the prevalence of $\mathrm{LVH}$ in a particular population is also influenced by selection bias, as patients with both higher blood pressure and more target organ damage are disproportionately referred to secondary or tertiary care centers. While most echocardiographic studies have relied on detection of increased LV mass to identify LVH, we have found it useful to use the $\mathrm{LV}$ wall thickness/chamber radius ratio [relative wall thickness $(10)$ ] to subclassify pa- tients into those with concentric or eccentric LVH based on the presence of elevated or normal relative wall thickness $(>$ or $\leq .430)$. Use of the same relative wall thickness in individuals with normal LV mass identifies increased relative wall thickness but normal LV mass in an additional $10 \%$ to $15 \%$ of uncomplicated hypertensive patients. We have coined the term "concentric remodeling" to describe this previously unrecognized LV geometric pattern (10).

The prevalence of LVH among hypertensive patients is influenced by gender, obesity, and possibly age. Sex-specific criteria for LV mass index identify $\mathrm{LVH}$ in more women than men with systemic hypertension. Reasons for this sex difference may include selective elimination of hypertensive men with $\mathrm{LVH}$ from populations because of accelerated complications of coronary artery disease as well as the greater increase in arterial pressure from lower levels in normal young women that is needed to meet diagnostic criteria for hypertension. The prevalence of hypertensive LVH, primarily the eccentric form, is increased $11 / 2$ - to 2 -fold by coexisting obesity, whereas the effect of advancing age mostly reflects age-related increases in blood pressure.

Evidence for heterogeneity of cardiac pathophysiologic patterns in hypertension has come from clinical and experimental studies of the clinical and functional correlates of previously described patterns of cardiac geometric adaptation. As shown in Table 1, blood pressure in hypertensive patients with concentric LVH is principally elevated by increased peripheral resistance with slightly above average normal cardiac output (10). The concentrically hypertrophied heart derives the increased work capacity needed to sustain moderately elevated blood pressure from increased LV mass and the mechanical advantage bestowed by high relative wall thickness despite decreased myocardial contractility $(10,45)$. In patients with eccentric hypertrophy, increased cardiac output with minimal or no elevation of peripheral resistance supports blood pressure elevation that is milder during normal activity than in the clinic $(9,10)$. Increased $\mathrm{LV}$ mass with normal relative wall thicknesses and roughly normal contractility but increased preload due to plasma volume expansion sustains LV ejection phase performance that is normal at rest but may be subnormal during exercise $(10,45-47)$. Patients with concentric LV remodelling have relatively mild hypertension despite markedly elevated peripheral resistance because cardiac output is subnormal (10). The mechanical advantage associated with high relative wall thickness sustains the pressure load at rest and during activity despite normal LV mass and reduced preload due to diminished plasma volume (45). Patients with normal LV geometry tend to have mild hypertension with above average normal peripheral resistances, cardiac outputs, or both (10). The mild overload is offset by slightly above average normal LV mass with normal contractility $(9,10,45)$. Colan et al. (48) reported that power lifters with concentric LVH and relative wall thickness out of proportion to arterial pressure had 
Table 1. Clinical and Hemodynamic Correlates of Patterns of Left Ventricular Geometric Adaptation to Hypertension*

\begin{tabular}{|c|c|c|c|c|c|}
\hline Characteristic & Ref. & $\begin{array}{c}\text { Normal } \\
\text { Geometry }\end{array}$ & $\begin{array}{l}\text { Concentric } \\
\text { Remodeling }\end{array}$ & $\begin{array}{c}\text { Eccentric } \\
\text { Hypertrophy }\end{array}$ & $\begin{array}{l}\text { Concentric } \\
\text { Hypertrophy }\end{array}$ \\
\hline Age & 10 & + & ++ & ++ & ++ \\
\hline Sex (Female/Male) & 10 & $=$ & $=$ & + & + \\
\hline Body Mass Index & 4,10 & + & + & ++ & ++ \\
\hline Cardiac Index & 10 & $=$ & -- & +++ & + \\
\hline Peripheral Resistance & 10 & + & +++ & $=$ & ++ \\
\hline Awake Ambulatory Blood Pressure & 9 & + & ++ & + & +++ \\
\hline Plasma Volume & 47 & $=$ & -- & ++ & $=$ \\
\hline Left Ventricular Mass & $9-10$ & $=$ to + & $=$ to + & ++ & +++ \\
\hline Relative Wall Thickness & $9-10$ & $=$ & ++ & $=$ & +++ \\
\hline
\end{tabular}

* Data reflect qualitative comparison between hypertensive patients and concurrently studied normotensive subjects. Characteristics are expressed from much greater $(+++)$ to much less $(--)$, or similar $(=)$.

supranormal resting LV fractional shortening, whereas runners with eccentric LVH had reduced chamber function. Thus, pure pressure or volume loads, whether "physiologic" or "pathologic," are similarly matched to patterns of ventricular geometry and function.

\section{Prognostic Implications of Hypertensive Left Ventricular Hypertrophy}

ECG LV hypertrophy is well known to predict morbidity and mortality in patients with hypertension $(49,50)$, in the general population $(51)$, and in catheterized patients with or without coronary artery obstruction (52), but it was uncertain whether these patterns derived their significance from cardiac hypertrophy or from ECG manifestations of myocardial ischemia. This uncertainty has been resolved by the demonstration that increased LV mass is a potent predictor of cardiovascular morbidity and mortality, independent of blood pressure or other risk factors.

In the first of a series of studies (53), we followed up 140 men with initially uncomplicated essential hypertension for $5 \mathrm{yr}$ to determine the incidence of "hard" cardiovascular morbid events (cardiac death, myocardial infarction, stroke, or angina pectoris requiring coronary bypass surgery). The $29 \%$ or $20 \%$ of the patients in whom baseline LV mass exceeded $125 \mathrm{~g} / \mathrm{m}^{2}$, a partition value for $\mathrm{LVH}$ chosen on the basis of previous findings in employed adults (54), had a roughly 4 -fold higher rate of morbid events $(7$ of 29 or $24 \%$ ) than the men without LVH (7 of 111 or $6 \%, p<0.01)(53)$.

We subsequently extended this study to more than 10-yr follow-up of 280 women and men with initially uncomplicated essential hypertension (55). A LV mass index of more than $125 \mathrm{~g} / \mathrm{m}^{2}$ strongly predicted all-cause mortality and cardiac death as well as myocardial infarction or the need for coronary revascularization. Considered as a continuous variable, LV mass index eliminated all conventional risk factors except age from multivariate models; after age adjustment, LV mass remained a strong predictor of adverse cardiovascular events. Subdivision of patients into groups with the four LV geometric patterns described above revealed that those with concentric LV hypertrophy (increased LV mass and relative wall thickness) had the highest rates of allcause mortality and cardiovascular morbid events, while patients with eccentric hypertrophy (increased LV mass alone) or concentric remodelling (increased relative wall thickness alone) had rates of morbidity that fell between those of patients with concentric hypertrophy and the low-risk group with normal LV geometry (55). Further analyses during up to 15 yr follow-up revealed an especially adverse outcome in patients with a LV mass index of more than 175 $\mathrm{g} / \mathrm{m}^{2}(56)$.

Other studies have confirmed and extended these findings by demonstrating that LV mass is a strong predictor, independent of blood pressure or other risk factors, of cardiac and cerebrovascular morbidity and mortality among middle-aged and elderly women and men in the general population (57-59), among patients with diverse forms of heart disease including hypertension (60-63), and among catheterized patients with and without coronary artery disease (64). A report from the Framingham Heart Study documented that LV mass strongly predicted all-cause and cardiac death and coronary heart disease events in adults older than $40 \mathrm{yr}$, and noted that "only LV mass index and age were strong and consistent predictors of all three outcome events in all age and sex subgroups" in analyses that included conventional risk factors (59). Of note, the same level of indexed LV mass $(140 \mathrm{~g} / \mathrm{m}$ of height) identified high-risk status in both women and men (59), similar to our finding that a LV mass of more than $125 \mathrm{~g} / \mathrm{m}^{2}$ predicted death or morbid events equally in both sexes (55). In another important study, Ghali et al. (64) documented that increased as opposed to normal LV mass predicted subsequent mortality more strongly (odds ratio $=3.7$ ) in catheterized patients without obstructive coronary artery disease than in those with stenosis of large coronary arteries (odds ratio $=1.9$ ).

One mechanism by which LVH may predispose to cardiac morbidity is by its association with systemic vascular hypertrophy and atherosclerosis (39, 
Table 2. LVH Regression and Prognosis: Available Data Proportion of Patients Suffering Morbid Events

\begin{tabular}{lrrrrr}
\hline & \multicolumn{2}{c}{ LV Mass Increase } & \multicolumn{2}{c}{ LVH on 2nd Study } \\
\cline { 2 - 3 } \cline { 5 - 6 } & \multicolumn{1}{c}{ Yes } & \multicolumn{1}{c}{ No } & Yes & No \\
\hline Koren (76) & $20 \%$ & $9 \%$ & $29 \%$ & $9 \%$ \\
Yurenev (77) & $39 \%$ & $12 \%$ & $35 \%$ & $9 \%$ \\
Levy* (78) & $13.2 \%$ & $6.7 \%$ & - & - \\
Muiesan ** (79) & $59 \%$ & $9 \%$ & $37 \%$ & $7 \%$ \\
Verdecchia (80) & - & - & $21 \%$ & $5 \%$ \\
\hline
\end{tabular}

* Change in ECG measure of LVH; other studies used echocardiographic LV mass. $* *$ No increase $=$ at least $10 \%$ decrease in LV mass.

65). In both clinical and experimental studies, LVH has been shown to amplify the morbid consequences of coronary artery obstruction $(64,66-69)$. However, although effective antihypertensive treatment has dramatically reduced stroke or heart failure mortality in hypertensive patients, it has had variable, significant or insignificant effects on coronary disease morbidity in controlled trials.

\section{Performance of the Hypertrophied Left Ventricle}

Echocardiography and radionuclide angiography make it possible to assess LV functional characteristics in unselected hypertensive patients. In most patients with mild to moderate hypertension, LV systolic performance at rest is normal or mildly increased. Supernormal LV ejection fraction or fractional shortening in patients or experimental animals with mild hypertension and little or no LVH has been interpreted as reflecting enhanced myocardial contractility (70-72), whereas marked concentric LVH in severely hypertensive patients facilitates LV contraction by reducing wall stress (73). However, a conceptual mismatch exists in analyses relating chamber size or shortening at the endocardium to the mean level of end-systolic wall stress, which is applied approximately at the LV midwall (74). When midwall-shortening-end-systolic stress relations were analyzed in relatively unselected hypertensive patients, patients with concentric LVH had decreased myocardial contractility and no significant hypercontractility was observed in patients without LVH (45).

Many hypertensive patients have normal resting LV function but abnormal ejection fraction responses to exercise $(44,75)$. We have found that abnormal exercise responses of both LV ejection fraction (46) and pulmonary capillary wedge pressure were associated with eccentric LV hypertrophy and with obesity, a cause of LV volume overload.

\section{Prognostic Implications of Reversal of Left Ventricular Hypertrophy}

Although it has long been presumed that regression of hypertensive LV hypertrophy would be clinically beneficial, only recently have data become available to support this hypothesis. Among 166 patients with initially uncomplicated essential hypertension who remained free of morbid events for approximately 5 yr between a baseline and follow-up echocardiogram, we found a higher risk of subsequent cardiovascular events in those in whom LV hypertrophy persisted or developed despite treatment than in those in whom LV mass remained normal or fell (76). In a cooperative study from Eastern Europe, Yurenev et al. (77) found that failure to decrease LV mass from baseline to the end of study or to the last annual echocardiogram before complications .occurred was strongly associated with the occurrence of morbid events.

The third study of this question, by Levy et al. (78), assessed 524 participants in the Framingham study (48\% women, nearly all white). Subjects all had $\mathrm{LVH}$ recognized by one or more of multiple ECG criteria; Cornell voltage $(\mathrm{RaVL}+\mathrm{SV} 3)$ at baseline and its change over 2-yr inter-examination intervals were related to cardiovascular events over the course of up to 18 2-yr follow-up periods (mean $=5.1$ ). Cornell voltage was used as the measure of $\mathrm{LVH}$ in both baseline and follow-up studies. Age, $\mathrm{BP}$, serum cholesterol level, diabetes, smoking, and baseline ECG voltage and repolarization were considered confounders. Comparison of groups that increased or decreased by a quartile of Cornell voltage - each about $25 \%$ of subjects - showed (Table 2) that individuals with increases in Cornell voltage were approximately twice as likely to suffer morbid events during 2-yr follow-up as those in whom voltage decreased.

The fourth relevant study, by Muiesan et al. (79), followed 151 white patients (42\% women) who had initially uncomplicated hypertension. Echocardiograms at baseline and at recall 7 to $13 \mathrm{yr}$ later (mostly before, but sometimes after, morbid events) were read blindly; intervening echocardiograms obtained for clinical purposes were also assessed. Other confounders taken into consideration were age, gender, body mass index, diabetes, blood lipids, and BP at baseline and the end of the study. Similar to the other studies, the presence of LVH on the follow-up echocardiogram was the factor most strongly related to morbid events; in addition, similar low rates of morbid events were observed in patients in whom baseline LVH regressed and in those with persistently normal LV mass (Table 2).

The fifth study of this topic, by Verdecchia et al. $(80)$, followed up 399 hypertensive adults who had baseline and follow-up echocardiograms a mean of $2.8 \mathrm{yr}$ apart for an additional interval of up to 7.5 yr. Analyses took into account relevant covariates including age, baseline 24-h BP, and baseline LV mass in Cox proportional hazards models. The rate of morbid events was significantly and independently higher in the 58 patients with persistent LV hypertrophy (6.35 per 100 patient-yr) than in the 48 in whom LVH regressed (1.8 per 100 patient-yr) or the 278 with persistent normal LV mass (1.76 per 100 patient-yr).

To summarize this topic, available data demonstrate a relatively consistent relation between LVH regression, with $50 \%$ or greater apparent reductions 
in the likelihood of cardiovascular events in the presence of a favorable change in LV mass, either as a categorical shift across a dividing line between "normal" LV mass and LVH or as an absolute decrease as opposed to an increase in LV mass. This has been observed in observational studies of a population cohort (78) and of hypertensive patients (76, 79-80), and in a trial of antihypertensive therapy (77). However, study populations have been relatively small, ranging from 151 to 524 individuals, almost entirely white and predominately male. The single treatment trial compared $\beta$-blocker- and diuretic-based treatment regimens, but did not specify the drugs added thereto. The available analyses have not modeled the mathematical relation between the change in LV mass or in ECG indices thereof and the proportionate or absolute change in the risk of subsequent morbid events, thus not meeting one important criterion for establishing LV mass as a surrogate end-point in hypertension trials $(81-83)$.

\section{Role of Cardiovascular Hypertrophy in the Evolution of Hypertensive Disease}

Hypertension and other risk factors, especially elevated cholesterol and glucose levels and cigarette smoking, help predict premature mortality and nonfatal morbid events, and their control variably reduces the incidence of events. However, the ability to predict risk and to reduce it by control of hypertension or other risk factors are both imperfect. These limitations occur in part because the progression from risk factor exposure to morbid events depends on the variable likelihood that individuals exposed to the same risk factors will progress through two stages: 1) the development of asymptomatic or "preclinical" anatomic and functional cardiovascular disease in response to standard risk factors and other variables, and 2) the precipitation of morbid events by progression of preclinical disease or by the action of additional "triggering" mechanisms in the presence of preclinical disease $(84,85)$. Advances in diagnostic methodology now allow noninvasive detection of $\mathrm{LVH}$ or other manifestations of preclinical disease, such as carotid atherosclerosis or renal dysfunction, in many asymptomatic individuals. Progress in elucidating stimuli that promote LVH and in defining its independent prognostic significance demonstrates that focusing separately on these two stages of disease evolution is a fruitful research strategy and may also be valuable in guiding clinical care. The closer relation of measures of preclinical disease rather than conventional risk factors to the subsequent risk of complications indicates that their detection improves clinical risk stratification. However, whether clinical outcome is improved or treatment cost is lowered by basing antihypertensive or antihyperlipidemic treatment decisions in part on the presence of LVH or other measures of preclinical cardiovascular disease needs to be tested before this strategy becomes the standard of care.

\section{Acknowledgements}

We thank Virginia Burns for her assistance in preparation of this manuscript.

\section{References}

1. Devereux RB, Pini R, Aurigemma GP, Roman MJ: Measurement of left ventricular mass: methodology and expertise. J Hypertens 1997; 15: 801-809.

2. de Simone G, Devereux RB, Daniels SR, Meyer RA: Gender differences in left ventricular growth. Hypertension 1995; 26: 979-983.

3. Hammond IW, Devereux RB, Alderman MH, Laragh JH: Relation of blood pressure and body build to left ventricular mass in normotensive and hypertensive employed adults. J Am Coll Cardiol, 1988; 12: 996-1004.

4. de Simone G, Devereux RB, Roman MJ, Alderman $\mathrm{MH}$, Laragh JH: Relation of obesity and gender to left ventricular hypertrophy in normotensive and hypertensive adults. Hypertension 1994; 23: 600-606.

5. Bella JN, Devereux RB, Roman MJ, et al: Relations of left ventricular mass to fat-free and adipose body mass: the Strong Heart Study. Circulation 1998; 98: 2538-2544.

6. de Simone G, Daniels SR, Devereux RB, et al: Left ventricular mass and body size in normotensive children and adults: assessment of allometric relations and of the impact of overweight. J Am Coll Cardiol 1992; 20: 1251-1260.

7. Devereux RB, Pickering TG, Harshfield GA, et al: Left ventricular hypertrophy in patients with hypertension: importance of blood pressure response to regularly recurring stress. Circulation 1983; 68: 470476.

8. Schnall PL, Schwartz JE, Landsbergis PA, Warren K, Pickering TG: Relation between job strain, alcohol and ambulatory blood pressure. Hypertension 1992; 19: 488-494.

9. Devereux RB, James GD, Pickering TG: What is normal blood pressure?: comparison of ambulatory pressure level and variability in patients with normal or abnormal left ventricular geometry. Am J Hypertens 1993; 6: 211s-215s.

10. Ganau A, Devereux RB, Roman MJ, et al: Patterns of left ventricular hypertrophy and geometric remodeling in essential hypertension. J Am Coll Cardiol 1992; 19: 1550-1558.

11. Levy D, Anderson KM, Savage DD, Kannel WB, Christiansen JC, Castelli WP: Echocardiographically detected left ventricular hypertrophy: prevalence and risk factors. Ann Intern Med 1988; 108: 7-13.

12. Schmieder RE, Messerli FH, Garavaglia GE, Nunez BE: Dietary salt intake: a determinant of cardiac involvement in essential hypertension. Circulation 1988; 78: 951-956.

13. Ganau A, Devereux RB, Pickering TG, et al: Relation of left ventricular hemodynamic load and contractile performance to left ventricular mass in hypertension. Circulation 1990; 81: 25-36.

14. Jones EC, Devereux RB, O'Grady MJ, et al: Relation of hemodynamic volume load to arterial and cardiac size. J Am Coll Cardiol 1997; 29: 1303-1310.

15. Devereux RB, Roman MJ, de Simone G, et al for the Strong Heart Study Investigators: Relations of left ventricular mass to demographic and hemodynamic variables in American Indians: the Strong Heart Study. Circulation 1997; 96: 1416-1423. 
16. Devereux RB, Roman MJ: Hypertensive cardiac hypertrophy: pathophysiologic and clinical considerations, in Laragh JH, Brenner BM (eds): Hypertension: Pathophysiology, Diagnosis, Treatment. 2nd ed., New York, Raven Press, 1995, pp409-432.

17. Schmieder RE, Langenfeld MRW, Friedrich A, Schobel HP, Gatzka CD, Weihprecht H: Angiotensin II related to sodium excretion modulates left ventricular structure in human essential hypertension. Circulation 1996; 94: 1304-1309.

18. Harrap SB, Dominiczak AF, Fraser R, et al: Plasma angiotensin II, predisposition to hypertension, and left ventricular size in healthy young adults. Circulation 1996; 93: 1148-1154.

19. Schroeder AP, Sihm I, Morn B, Thygesen K, Pedersen EB, Lederballe O: Influence of humoral and neurohormonal factors on cardiovascular hypertrophy in untreated essential hypertensives. Am J Hypertens 1996; 9: 207-215.

20. Schmieder RE, Martus P, Klingbeil A: Reversal of left ventricular hypertrophy in essential hypertension: meta-analysis of randomized double-blind studies. JAMA 1996; 275: 1507-1513.

21. Roman MJ, Alderman MH, Pickering TG, et al: Differential effects of angiotensin converting enzyme inhibition and diuretic therapy on reductions in ambulatory blood pressure, left ventricular mass, and vascular hypertrophy. Am J Hypertens 1998; 11: 387396.

22. Buttrick P, Kaplan M, Camargo MJF, et al: The influence of dietary salt and plasma renin activity on myosin heavy chain gene expression in rat hearts. Am J Hypertens 1993; 6: 579-585.

23. Celentano A, Vaccaro O, Tammaro P, et al: Early abnormalities of cardiac function in non-insulin-dependent diabetes mellitus and impaired glucose tolerance. Am J Cardiol 1995; 76: 1173-1176.

24. Galderisi M, Anderson KM, Wilson PW, Levy D: Echocardiographic evidence for the existence of a distinct diabetic cardiomyopathy (the Framingham Heart Study). Am J Cardiol 1991; 68: 85-89.

25. Devereux RB, Roman MJ, Ilercil A, et al: Impact of diabetes on cardiac structure and function in American Indians: the strong heart study. J Am Coll Cardiol 1997; 29: 448A.

26. Radice M, Alli C, Avanzini F, et al: Left ventricular structure and function in normotensive adolescents with a genetic predisposition to hypertension. Am Heart J 1986; 111: 115-120.

27. Ravogli A, Trazzi S, Villani A, et al: Early 24-hour blood pressure elevation in normotensive subjects with parental hypertension. Hypertension 1990; 16: 491-497.

28. Harshfield GA, Grim CE, Hwang C, Savage DD, Anderson SJ: Genetic and environmental influences on echocardiographically determined left ventricular mass in black twins. Am J Hypertens 1990; 3: 538543.

29. Verhaaren HA, Schieken RM, Mosteller M, Hewitt JK, Eaves LJ, Nance WE: Bivariate genetic analysis of left ventricular mass and weight in pubertal twins (the Medical College of Virginia Twin Study). Am J Cardiol 1991; 68: 661-668.

30. Fagard R, Van der Brocke C, Bielen E, Amery A: Maximum oxygen uptake and cardiac size and function in twins. Am J Cardiol 1987; 60: 1362-1367.

31. Post WS, Larson MG, Myers RH, Galderisi M, Levy D: Heritability of left ventricular mass: the Framingham Heart Study. Hypertension 1997; 30: 1025-1028.

32. Bella JN, MacCluer, J, North K, et al: Heritability of left ventricular dimensions and mass: the Strong Heart
Study (Abstract). Circulation 1998; 98

33. Arnett DK, Rao DC, Oberman A, Kitzman D, Hopkins P, Devereux RB: Strong heritability of left ventricular mass in hypertensive African-American and white adults: the hyperGEN study (Abstract). Circulation 1998; 98 (Suppl 1): 1-29.

34. Mahoney CT, Schieken RM, Clarke WR, Lauer RM: Left ventricular mass and exercise responses predict future blood pressure: the Muscatine study. Hypertension 1988; 12: 206-213.

35. de Simone G, Devereux RB, Roman MJ, Schlussel $\mathrm{Y}$, Alderman $\mathrm{MH}$, Laragh JH: Echocardiographic left ventricular mass and electrolyte intake predict subsequent arterial hypertension in initially normotensive adults. Ann Intern Med 1991; 114: 202209.

36. Iso $\mathrm{H}$, Kiyama $\mathrm{M}$, Doi $\mathrm{M}$, et al: Left ventricular mass and subsequent blood pressure changes among middle-aged men in rural and urban Japanese populations. Circulation 1994; 89: 1717-1724.

37. Post WS, Larson MG, Levy D: Impact of left ventricular structure on the incidence of hypertension: the Framingham Heart Study. Circulation 1994; 90: 179-185.

38. Liu JE, Roman MJ, Spitzer MC, et al: Elevated ambulatory with normal clinic blood pressure ("white coat normotension") is associated with cardiac and arterial target organ damage. Am J Hypertens 1995; 8: $42 \mathrm{~A}$

39. Roman MJ, Saba PS, Pini R, et al: Parallel cardiac and vascular adaptation in hypertension. Circulation 1992; 86: 1909-1918.

40. Saba PS, Roman MJ, Pini R, Ganau A, Devereux RB: Relation of arterial pressure waveforms to left ventricular and carotid anatomy in normotensive subjects. J Am Coll Cardiol 1993; 22: 1873-1880.

41. Devereux RB, de Simone G, Pickering TG, Schwartz $\mathrm{JE}$, Roman MJ: Relation of left ventricular midwall function to cardiovascular risk factors and arterial structure and function. Hypertension 1998; 31: 929936.

42. Savage DD, Drayer JIM, Henry WL, et al: Echocardiographic assessment of cardiac anatomy and function in hypertensive subjects. Circulation 1979; 59: 623-632.

43. Devereux RB, Casale PN, Hammond IW, et al: Echocardiographic detection of pressure-overload left ventricular hypertrophy: effect of criteria and patient population. J Clin Hypertens 1987; 3: 66-78.

44. Devereux RB, Casale PN, Wallerson DC, et al: Costeffectiveness of echocardiography and electrocardiography for detection of left ventricular hypertrophy in patients with systemic hypertension. Hypertension 1987; 9 (Suppl 2): 69-76.

45. de Simone G, Devereux RB, Roman MJ, et al: Assessment of left ventricular function by the midwall fractional shortening-end-systolic stress relation in human hypertension. J Am Coll Cardiol 1994; 23: 1444-1451.

46. Blake J, Devereux RB, Borer JS, Szulc M, Pappas TW, Laragh JH: Relation of obesity, high sodium intake and eccentric left ventricular hypertrophy to left ventricular exercise dysfunction in essential hypertension. Am J Med 1990; 88: 477-485.

47. Ganau A, Arru A, Saba PS, et al: Stroke volume and left heart anatomy in relation to plasma volume in essential hypertension. J Hypertens 1991; 9 (Suppl 6): s150-s151.

48. Colan SD, Sanders SP, Borow KM: Physiologic hypertrophy: effects on left ventricular systolic mechanics in athletes. J Am Coll Cardiol 1987; 9: 
776-783.

49. Sokolow M, Perloff D: The prognosis of essential hypertension treated conservatively. Circulation 1961; 23: 697-706.

50. Breslin DJ, Gifford RW Jr, Fairbairn JF II: Essential hypertension: a twenty-year follow-up study. Circulation 1966; 33: 87-97.

51. Kannel WB, Castelli WP, McNamara PM, McKee PA, Feinleib M: Role of blood pressure in the development of congestive heart failure: the Framingham Heart Study. N Engl J Med 1972; 287: 781-787.

52. Sullivan JM, Vander Zwaag R, El-Zeky F, Ramanathan KB, Mirvis DM: Left ventricular hypertrophy: effect on survival. J Am Coll Cardiol 1993; 22: 508-513.

53. Casale PN, Devereux RB, Milner M, et al: Value of echocardiographic measurement of left ventricular mass in predicting cardiovascular morbid events in hypertensive men. Ann Intern Med 1986; 105: 173178.

54. Hammond IW, Devereux RB, Alderman MH, et al: The prevalence and correlates of echocardiographic left ventricular hypertrophy among employed patients with uncomplicated hypertension. J Am Coll Cardiol 1986; 7: 639-650.

55. Koren MJ, Devereux RB, Casale PN, Savage DD, Laragh JH: Relation of left ventricular mass and geometry to morbidity and mortality in men and women with essential hypertension. Ann Intern Med 1991; 114: 345-352.

56. Mensah GA, Pappas TW, Koren MJ, Ulin RJ, Laragh JH, Devereux RB: Comparison of classification of hypertension severity by blood pressure level and World Health Organization criteria for prediction of concurrent cardiac abnormalities and subsequent complications in essential hypertension. $J$ Hypertens 1993; 11: 1429-1440.

57. Bikkina M, Levy D, Evans JC, et al: Left ventricular mass and risk of stroke in an elderly cohort: the Framingham Heart Study. JAMA 1994; 272: 33-36.

58. Levy D, Garrison RJ, Savage DD, Kannel WB, Castelli WP: Left ventricular mass and incidence of coronary heart disease in an elderly cohort: the Framingham Study. Ann Intern Med 1989; 110: 101-108.

59. Levy D, Garrison RJ, Savage DD, Kannel WB, Castelli WP: Prognostic implications of echocardiographically determined left ventricular mass in the Framingham Heart Study. $N$ Engl J Med 1990; 322: 1561-1566.

60. Aronow WS, Epstein S, Koenigsberg M, Schwartz KS: Usefulness of echocardiographic left ventricular hypertrophy, ventricular tachycardia and complex ventricular arrhythmias in predicting ventricular fibrillation or sudden death in elderly patients. $A m J$ Cardiol 1988; 62: 1124-1125.

61. Cooper RS, Castaner A, Simmons B, Suntanan V, Chali JL, Mar M: Left ventricular hypertrophy is associated with worse survival independent of ventricular function and number of coronary arteries severely narrowed. Am J Cardiol 1990; 65: 441-445.

62. Parfrey PS, Harnett JD, Griffiths SM, et al: The clinical course of left ventricular hypertrophy in dialysis patients. Nephron 1990; 55: 114-120.

63. Silberberg JS, Barre PE, Prichard SS, Sniderman $\mathrm{AD}$ : Impact of left ventricular hypertrophy on survival in end-stage renal disease. Kidney Int 1989; 36: 286-290.

64. Ghali JK, Liao Y, Simmons B, Castaner A, Cao G, Cooper RS: The prognostic role of left ventricular hypertrophy in patients with or without coronary artery disease. Ann Intern Med 1992; 117: 831-836.
65. Roman MJ, Pickering TG, Schwartz JE, Pini R, Devereux RB: The association of carotid atherosclerosis and left ventricular hypertrophy. J Am Coll Cardiol 1995; 25: 83-90.

66. Koyanagi S, Eastham CL, Harrison DG, Marcus ML: Increased size of myocardial infarction in dogs with chronic hypertension and left ventricular hypertrophy. Circ Res 1982; 50: 55-62.

67. Dellsperger KC, Clothier JL, Hartnett JA, Hann LM, Marcus ML: Acceleration of the wavefront of myocardial necrosis by chronic hypertension and left ventricular hypertrophy in dogs. Circ Res 1988; 63: 87-96.

68. Koyanagi S, Eastham CL, Marcus ML: Effects of chronic hypertension and left ventricular hypertrophy on the incidence of sudden cardiac death after coronary artery occlusion in conscious dogs. Circulation 1982; 65: 1192-1197.

69. Inou T, Lambeth WC Jr, Koyanagi S, Harrison DG, Eastham CL, Marcus ML: Relative importance of hypertension after coronary occlusion in chronic hypertensive dogs with LVH. Am J Physiol 1987; 253: H1148-H1158.

70. Lutas EM, Devereux RB, Reis G, et al: Increased cardiac performance in mild essential hypertension: left ventricular mechanics. Hypertension 1985; 7: 979-988.

71. Hartford M, Wikstrand JCM, Wallentin I, Ljungman SMG, Berglund GL: Left ventricular wall stress and systolic function in untreated primary hypertension. Hypertension 1985; 7: 97-104.

72. de Simone G, DiLorenzo L, Costantino G, Moccia D, Buonissimo S, de Vitiis O: Supernormal contractility in primary hypertension without left ventricular hypertrophy. Hypertension 1988; 11: 457-463.

73. Blake J, Devereux RB, Herrold EMcM, et al: Relation of concentric left ventricular hypertrophy and extracardiac target organ damage to supranormal left ventricular performance in established essential hypertension. Am J Cardiol 1988; 62: 246-252.

74. Shimizu G, Hirota Y, Kita Y, Kawamura K, Saito T, Gaasch WH: Left ventricular midwall mechanics in systemic arterial hypertension: myocardial function is depressed in pressure-overload hypertrophy. Circulation 1991; 83: 1676-1684.

75. Schussheim AE, Devereux RB, de Simone G, Borer JS, Herrold EMcM, Laragh JH: Usefulness of subnormal midwall fractional shortening in predicting left ventricular exercise dysfunction in asymptomatic patients with systemic hypertension. Am J Cardiol 1997; 79: 1070-1074.

76. Koren MJ, Ulin RJ, Laragh JH, Devereux RB: Reduction of left ventricular mass during treatment of essential hypertension is associated with improved prognosis. Am J Hypertens 1991; 4: 1A.

77. Yurenev AP, Dyakonova HG, Novikov ID, et al: Management of essential hypertension in patients with different degrees of left ventricular hypertrophy: multicenter trial. Am J Hypertens 1992; 5: 182s-189s.

78. Levy D, Salomon M, D'Agostino RB, Belanger AJ, Kannel WB: Prognostic implications of baseline electrocardiographic features and their serial changes in subjects with left ventricular hypertrophy. Circulation 1994; 90: 1786-1793.

79. Muiesan ML, Salvetti M, Rizzoni D, Castellano M, Donato F, Agabiti-Rosei E: Association of change in left ventricular mass with prognosis during long-term antihypertensive treatment. J Hypertens 1995; 13: 1091-1105.

80. Verdecchia P, Schillaci G, Borgioni C, et al: Prognostic value of serial changes in left ventricular mass 
in essential hypertension. Am J Hypertens 1997; 10: 25A (Abstract).

81. Devereux RB, Agabiti-Rosei E, Dahlof B, et al: Regression of left ventricular hypertrophy as a surrogate end-point for morbid events in hypertension treatment trials. J Hypertens 1996; 14 (Suppl 2): s95-s102.

82. Devereux RB, Okin PM, Roman MJ: Pre-clinical cardiovascular disease and surrogate end-points in hypertension: Does race influence target organ damage independent of blood pressure? Ethnicity Dis 1998; 8: 138-148.
83. Prentice RL: Surrogate end-points in clinical trials: definition and operational criteria. Stat Med 1989; 8: 431-440.

84. Devereux RB, Alderman $\mathrm{MH}$ : Role of preclinical cardiovascular disease in the evolution from risk factor exposure to clinical morbid events. Circulation 1993; 88: 1444-1455.

85. Muller JE, Abela GS, Nesto RW, Tofler GH: Triggers, acute risk factors, and vulnerable plaques: the lexicon of a new frontier. J Am Coll Cardiol 1994; 23: $809-813$. 